\title{
Influence of E-Tourism in Indias GDP
}

\author{
Soumya k \\ Lectuer in Commerce MES Ponnani College
}

\begin{abstract}
Tourism is an activity that is mainly Carrie out for recreational and leisure time purposes. This activity has proved vital for many countries developing as well as developed count ries. It has been proved in case of India. During the last decade of $20^{\text {th }}$ century, India saw the emergence of e-tourism, its innovation and growth. It is because of the online revolution and its utility where the tourists are more interested to get information on destinations, facilities, availabilities, prices, geography \& climate and present status of friendly relation. This led to the development of e-commerce strategies in tourism industry and more services in the form of online hotel booking, flight booking, car booking, bus booking came into forefront as online services provided by the big online travel industries like Makemytrip.com, Yatra.com, Cleartrip.com, Ezeegol.com, Arzoo.com, Travelguru.com, Travel.indiatimes.com. On these sites, the travellers have wide option of exploring details of hotels, flights, cars, buses and other allied services. Incredible India is the most sough-after tourist destinations of traveller since the ancient time when the Indian subcontinent was explored by the outsiders. India had become a home to many visitors and invaders starting from the Aryans invasion during the prehistoric era of India.Developing country like India tourism has become one of the major sectors of the economy, contributing to a large proportion to GDP and employment opportunities. Tourism is one of the fastest growing service industry in the country with great potentials for its further expansion and diversification. Tourism industry plays a major role in any country's economic development.
\end{abstract}

Keywords: E-commerce, E-tourism, economic development. , GDP, online revolution.

\section{Introduction}

The land of India represents an example of diversified geographical features with its mountain ranges, valleys, desert regions, tropical rain forests, fertile plains, dry plateaus, coastal areas etc. that attracted the tourists from all over the world to give a glimpse to this mysterious land of geographical diversities. The land is interlocked by the Himalayan ranges in the north, and three sides by water - the Arabian Sea, Bay of Bengal, and the Indian Ocean - with a long history and diverse culture.

Tourism in India is economically important and is growing rapidly. The World Travel \& Tourism Council calculated that tourism generated ₹8.31 lakh crore (US\$120 billion) or 6.3\% of the nation's GDP in 2015 and supported 37.315 million jobs, $8.7 \%$ of its total employment. During the last decade of 20th century, India saw the emergence of e-tourism, its innovation and growth. It is because of the online revolution and its utility where the tourists are more interested to get information on destinations, facilities, availabilities, prices, geography \& climate and present status of friendly relation. This led to the development of e-commerce strategies in tourism industry and more services in the form of online hotel booking, flight booking, car booking, bus booking came into forefront as online services . Tourism in India has a strong relevance to economic development, cultural growth and national integration. As mentioned earlier, India is a vast country of great beauty and diversity and her tourist potential is equally vast Organised tourism in India began in the 1950s with the genesis of planned development. Over the years, Indian tourism has grown considerably as is indicated by the arrival of foreign tourists This shows that the number of foreign tourists visiting India has increased substantially after the beginning of the planned era.

\section{E- Tourism In India}

The revolution of the Internet and information and communication technologies (ICTs) in India has had already insightful repercussions for the tourism industry. A whole system of Communication Technologies and the Internet has been rapidly diffused throughout Indian tourism sectors. Subsequently, online travel bookings and associated travel services are accepted as one of the most thriving e-commerce implementations. Tourism has closely been connected to progress of Information and communication system for over 10 years in India. The tourism industry initially concentrated on utilizing information system to increase efficiency in processing of information within and managing distribution. During the last decade of 20th century, India saw the emergence of e-tourism, its innovation and growth. It is because of the online revolution and its utility where the tourists are more interested to get information on destinations, facilities, availabilities, prices, geography \& climate and present status of friendly relation. This led to the development of e-commerce 
strategies in tourism industry and more services in the form of online hotel booking, flight booking, car booking, bus booking came into forefront as online services provided by the big online travel companies such as Travelchacha.com, Makemytrip.com, Yatra.com, Cleartrip.com, Ezeego1.com, Arzoo.com, Travelguru.com, Travel.indiatimes. $5 \mathrm{com}$, ixigo.com, travelocity.co.in etc. On these sites, the travellers have wide option of exploring details of hotels, flights, cars, buses and other allied services. At present, the information and communication technology supports all operative, structural, strategic and marketing levels to facilitate global interaction among suppliers, intermediaries and consumers around the world and Indian players. Now in India the online travel bookings and associated travel services are recognized as one of the most successful ecommerce implementations. Many tourism-related organisations had to go through a major business processes re-engineering to capitalise on the emerging technologies in order to transform their service process and data handling to match the global standard. More specifically, the opening up of the Indian market for foreign players and the changes in the aviation industry policy attracted large number of international players across the world to establish their business centres in India.

The foreign players were brought in their technical know how's and their innovative business process into the Indian market that contributed to the forceful adoption on technology and information system of tourism players to stay alive in the competitors. The global business dimension also increased the demand of international consumptions and tourism related services both domestic and international, which made the tourism associates to re-engineer their products and process to match the expectation of the market. According to $2013 \mathrm{CNN}$ global travel survey, India is now one of the top tourism destinations in Asia as it has received 3.3 million foreign tourists during the first half of this year. Currently the Indian market is well equipped and competitive as any of the international tourism market across the world as it was able to adapt to the rapidly changing IT enabled tourism process and service delivery by partnering with international participants. The amount of foreign direct investments (FDI) inflow into the hotel and tourism sector during April 2000 to April 2013 was worth US\$ 6,664.20 million, as per data provided by Department of Industrial Policy and Promotion (DIPP), Ministry of Commerce.

\section{E-Tourism Players}

The main actors in the tourism industry include governments, tour operators, hotels, airlines and other transport operators, and tourists or consumers. Each of these actors has a stake in the development of the electronic market. Each is expected to be affected in different ways by the changes brought about by electronic commerce. The concerns and interests of these stakeholders need to be addressed in order to ensure that changes are managed and promoted to the benefit of all. Each of these players utilise information and communication technology in their processes to complement each other on making e-tourism efficient. Some of the e-tourism activities performed by the main stakeholders are discussed below.

$\checkmark$ E airlines

$\checkmark$ E hospitality

$\checkmark$ Edestination

$\checkmark \quad$ E travel agency

$\checkmark \quad$ E tour operators

\subsection{E airlines:}

E-airlies focus on the following aspects:

Improving the accessibility,

Customer relationship and their business associates;

Electronic bookings

Online ticketing;

Yield management

E-auctions for very last minute available seats

Disintermediation and restructuring of agency charge schemes

Increasing the productivity of the new channel in electronic distribution

Players like Air Asia, Tiger airways, all classical examples for e-airlines that work on customising the services based on the customers to work out on low cost fares. The electronic mode allows the customers to choose the options on unbundled packages in terms of travel insurance, additional luggage, Food, Choice of seat etc. The Air Asia Web page displaying the online air ticket information and promotions, the web page contain provisions for checking availability, flight information, cost, etc. These web pages are easy and customer friendly and keeps promoting their e-airline initiatives through news papers, through promotions. 


\subsection{E-Hospitality}

As they do not have extensive ICT departments and expertise, they can easily access up-to-date applications and benefit from the collective knowledge accumulated by ASP providers without having to invest extensively in technology or expertise building e-hospitality is beyond just distributing, servicing, as it offers more than that by supporting proven hospitality and technology products for the Hospitality Industry. Additionally, e -Hospitality offer support and services beyond just that of a front desk system vendor, therefore it is postured to assist properties with all aspects of the front desk and associated guest amenities from the phone system and voice mail to Pay per View (PPV) movies, secure high speed in rooms, lobby kiosks, and even guest printing/faxing from the guest rooms.

One of the most promising developments in hospitality is 'application service providers (ASPs)'. ASPs will be increasingly more involved in hosting a number of business applications for hospitality organisations. ASPs are ideal for hotels, especially for smaller- to mid-sized ones, that want to leverage the best vertical and enterprise support applications on the market without having to deal with the technology or pay for more functionality than

\subsection{E-Tour Operators}

Leisure travellers often purchase "packages," consisting of charter flights and accommodation, arranged by tour operators. Tour operators tend to pre-book these products and distribute them through brochures displayed in travel agencies. Recent times in India, the tour operators realised the benefits of utilising communication technology in organising, promoting, distributing and coordinating their packages. Gradually, all major tour operators developed or acquired databases and established electronic links with travel agencies, aiming to reduce their information handling costs and increase the speed of information transfer and retrieval. This improved their productivity and capacity management whilst enhancing their services to agencies and consumers. Tour operators also utilised their CRSs for market intelligence, in order to adjust their supply to demand fluctuations, as well as to monitor the booking progress and productivity of travel agencies.

\subsection{E-Travel Agencies}

Information and communication technology has become a major tool for travel agencies as they provide information and reservation facilities and support the intermediation between consumers and principals. Travel agencies operate various reservation systems, which mainly enable them to check availability and make reservations for tourism products. Until recently GDSs have been critical for business travel agencies to access information and make reservations on scheduled airlines, hotel chains, car rentals and a variety of ancillary services. GDSs help construct complicated itineraries, while they provide up to-date schedules, prices and availability information, as well as an effective reservation method. In addition, they offered internal management modules integrating the "back office" (accounting, commission monitor, personnel) and "front office" (customers' history, itinerary construction, ticketing and communication with suppliers).

\subsection{E-Destinations}

Destinations are amalgams of tourism products, facilities and services which compose the total tourism expertise under one brand name. Traditionally the planning, management and coordination functions of destinations have been undertaken by either the public sector (at national, regional or local level) or by partnerships between stakeholders of the local tourism industry.

\section{Contribution Of E Tourism In Indian GDP}

The Tourism sector of Indian economy is at present experiencing a huge growth. The Tourism sector of Indian economy has become one of the major industrial sectors under the Indian economy. The tourism industry earns foreign exchanges worth `21,828 core. Previous year the growth rate of the tourism sector of Indian economy was recorded as $17.3 \%$.

The growth in the tourism industry is due to the rise in the arrival of more and more foreign tourists and the increase in the number of domestic tourists. Indian Tourism offers a potpourri of different cultures, traditions, festivals, and places of interest. There are a lot of options for the tourists. India is a country with rich cultural and traditional diversity. This aspect is even reflected in its tourism.

The travel and tourism industry contributed a total of 124.8 billion U.S. dollars to GDP in India in 2015 - this accounted for approximately six percent of India's total GDP. The industry directly provided more than 23.5 million jobs in that year. A 2014 study found that India was one of the fastest-growing tourism destinations worldwide. Placed eleventh in the list, the direct contribution of travel and tourism to GDP in India was expected to grow an average of 6.4 percent annually between 2014 and 2024.

In 2015 , there were 8.03 million international tourist arrivals in India. This was a large increase from the 2.65 million seen just 15 years earlier in 2000. The largest source market for visitors to India was the 
United States, followed by Bangladesh and the United Kingdom. Outbound travel from India is also on the rise: approximately 1.1 million Indian nationals traveled to the U.S. in 2015. This figure was forecasted to rise to 1.41 million in 2020. Europe is even more popular, with 2.5 million Indian tourists traveling there in 2015.

Hotel prices in India are generally low, only rising above 100 U.S. dollars once in the first half of 2015 when average daily rates reached 102.78 dollars in February. Since 2009, the occupancy rate of the hotel industry in India has remained stable at around 60 percent annually. Over the last 15 years, the highest occupancy rate was seen in the fiscal year ended 2006, when it reached 71.5 percent.

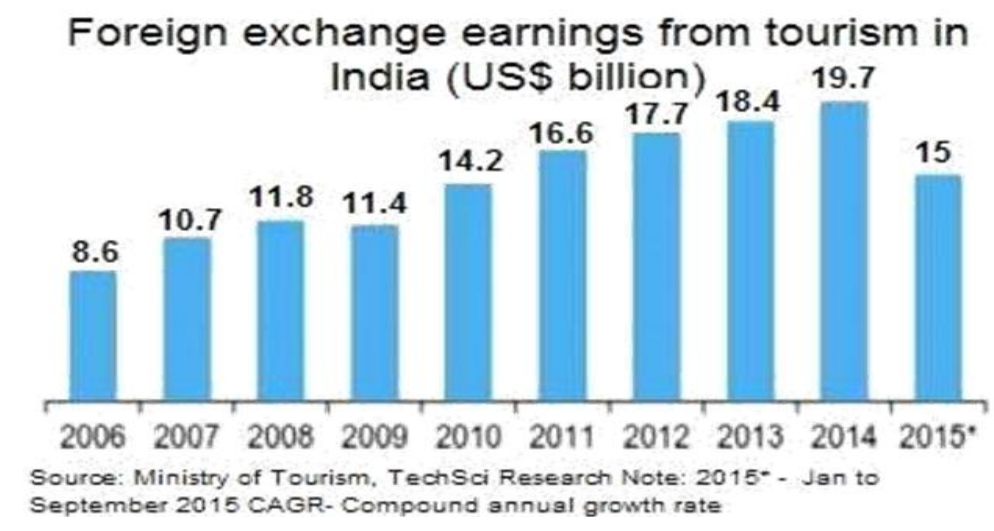

Expected Foriegners

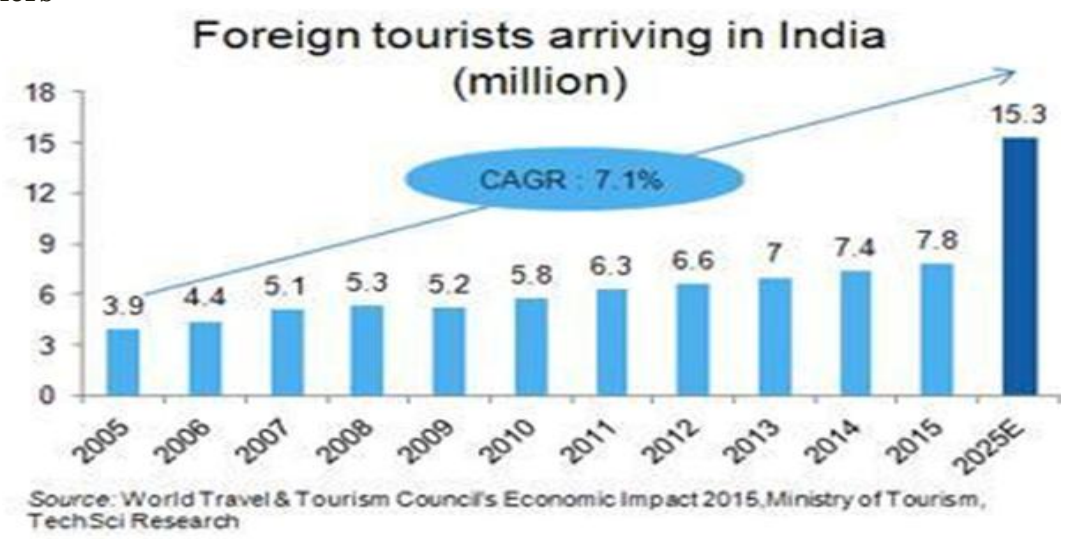

\section{Conclusion}

The emergence of Information technology has transformed the tourism and travel industry beyond comprehension. ICT has made the industry more competitive and attractive to both customers and services providers apart from other stake holders and distribution partners. Indian tourism market was able to adapt to the ICT interference and they understood the global competition and growing demand for the e-tourism in the other countries. The tourism merged with IT in the early stage when Computer Reservations Systems (CRSs) came into existence, then in another 10 years time, with Global Distribution Systems (GDSs), and finally an integrated approach called Internet Distribution System (IDS) that utilised electronic media as well as communication technology evolved. Electronic tourism comprises of e-airlines, e-travel agencies, e-hospitality management e-tour operators and e-destinations. Today the tourism market is rapidly changing and is looking continuously grow and change business and the process that will increase the efficiency of the tourism consumption.

\section{References}

[1]. Jennings, G. (2006) Tourism Research (John Wiley \& Sons,Australia).,

[2]. Veal, A. J, (2006) Research Methods for Leisure and Tourism: A Practical Guide, 3rd ed (Prentice Hall),

[3]. Smith, S. (2010) Practical Tourism Research (CABI).

[4]. Cudny, W., Gosik, B., Piech, M., Rouba, R. (2011)

[5]. Buhalis, D., 2003, eTourism: Information Technology for strategic tourism management.

[6]. Buhalis, D., A.M. Tjoa and J. Jafari 1998, Information and Communication

[7]. Technologies in tourism, ENTER'98 Conference Proceedings, Istanbul, Springer-Verlag, Wien-New York.

[8]. Buhalis, D., and Schertler, W., 1999, Information and Communication Technologies in tourism, ENTER'99, Springer-Verlag, Wien-New York, ISBN 3-211-83258-0. 